\title{
Rare allele enrichment and detection by allele-specific PCR, competitive probe blocking, and melting analysis
}

Luming Zhou, Ying Wang, and Carl T. Wittwer

Department of Pathology, University of Utah, Salt Lake City, UT, USA

BioTechniques 50:311-318 (May 2011) doi 10.2144/000113668

Keywords: Allele-specific; competitive blocking PCR; melting analysis; rare allele enrichment; $B R A F$

Supplementary material for this article is available at www.BioTechniques.com/article/113668.

Differential amplification of variant and wild-type alleles by PCR is often used for rare allele enrichment. We have combined allele-specific PCR, competitive probe blocking, asymmetric PCR, and melting analysis to enhance rare allele detection in a homogeneous system. Unlabeled, dual hybridization or molecular beacon probes were used for competitive blocking of the wild-type allele at a concentration 10 times that of the allele-specific primer. In each case, rare alleles were detected by probe melting analysis at a sensitivity of $>0.001 \%$ ( 1 variant copy within 100,000 wildtype copies), providing single copy detection in typical PCRs. Ninety-one thyroid biopsies were tested for the $B R A F$ mutation p.V600E (c.1799 T>A) by both dual hybridization probes without enrichment and an allele-specific, competitive blocking melting analysis with unlabeled probes. Eighty-seven samples were concordant between methods ( 43 positive, 44 negative), while 4 samples that were negative by direct analysis became positive after enrichment. Probes that both block wild-type amplification and detect rare variants by melting analysis improve the detection sensitivity of allele-specific PCR for rare alleles. In particular, melting analysis using unlabeled probes and amplification by rapid-cycle PCR provides cost-effective and fast enrichment and detection of rare alleles.

The ability to detect low levels of sequence variants among mostly wild-type DNA is critical for early cancer detection, prenatal testing, and infectious diseases. In cancer, low-level mutations $(<10 \%)$ are usually below the detection limits of most genotyping techniques, including standard sequencing. Many moderate- to high-sensitivity PCR-based methods have been developed over the past two decades to enrich minority alleles. Limiting the denaturation temperature of PCR can be used to enrich known and unknown mutations (1). However, careful control of cycling temperatures is necessary and multiple amplicons can seldom be analyzed on the same plate. Allele-specific PCR methods to enrich known mutations include the amplification refractory mutation system (2), mutant allele-specific amplification (3), and methods that incorporate locked nucleic acids for increased specificity $(4,5)$. Alternatively, nucleic acid clamps can be used to block wild-type amplification, including peptide nucleic acid (6-9) and locked nucleic acid (10-12) probes. In some methods, primers that select mutant DNA are combined with probes that block wild-type amplification. In one version, the blocking probe competes with the allele-specific primer $(13,14)$ for increased sensitivity. However, all these methods can result in false positives when sensitivities below $0.1 \%$ are attempted (13-15).

Herein we enhance allele-specific PCR with a competitive blocking probe by asymmetric amplification and probe melting analysis to increase sensitivity and specificity. Unlabeled probes $(16,17)$, dual-hybridization probes $(18,19)$, and molecular beacons (20) are used as probes and also identify rare alleles by melting analysis. The method is demonstrated on the $B R A F$ point mutation p.V600E (c.1799 T>A), the most common change in papillary thyroid carcinoma (21) that occurs in more than $80 \%$ of cases studied $(21,22)$.

\section{Materials and methods}

DNA samples

DNA from normal human blood and a homozygous $B R A F$ c.1799T $>$ A cell line (Cat. no. HTB-72; ATCC, Manassas, VA, USA) were extracted by salting out (Gentra, Puregene, Qiagen, Valencia, CA, USA). DNA concentrations and quality were assessed by absorbance (NanoDrop, Wilmington, DE,
USA) with minor adjustments by PCR quantification cycle (Cq). Different mutation percentages $(10 \%, 1 \%, 0.1 \%, 0.01 \%, 0.001 \%$, and $0.0001 \%$ ) were obtained by mixing.

Clinical samples were obtained from a total of 47 patients. Forty-four of these patients had samples with both surgical excision tissue and fine-needle aspirates of thyroid nodules while the remaining 3 patients had only needle aspirates. All samples were de-identified and blinded by ARUP Laboratories (Salt Lake City, UT, USA) after testing for $B R A F$ c.1799A using dual-hybridization probes as described previously (23).

Oligonucleotides

The allele-specific primer 5'-GTGATTTTGGTCTAGCTACAGㅅ-3', reverse primer 5'-TCAGTGGAAAAATAGCCTCAATTC-3' and unlabeled probe 5'-TCTAGCTACAG TGAAATCTCGATG-P-3' were synthesized at the University of Utah core facility by standard phosphoramidite synthesis. Dualhybridization probes 5'-AGCTACAGTGAAATCTCGATGGAG-fluorescein-3' and 5'-LCRed640-GGTCCCATCAGTTTGAACAGTTGTCTGGA- 


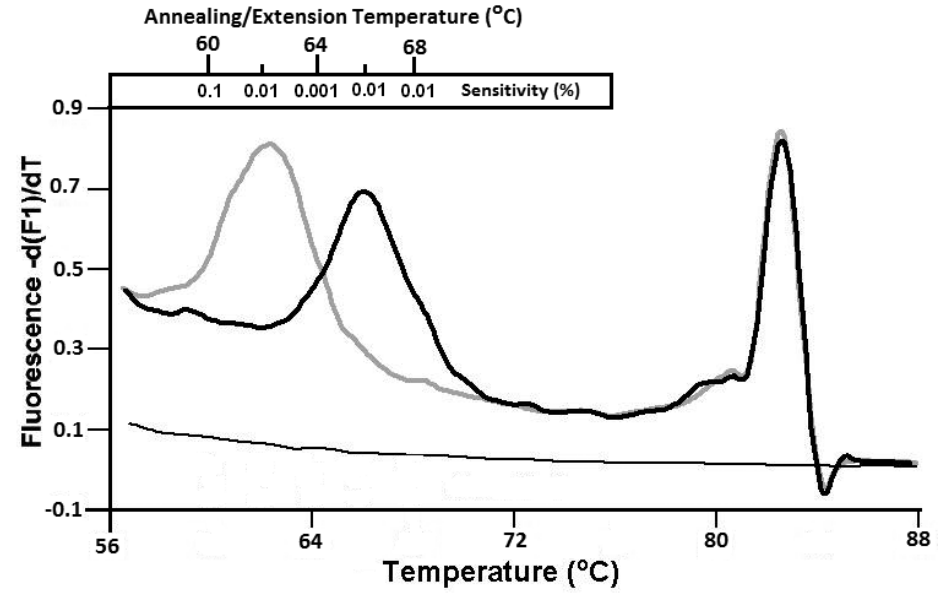

Figure 1. Derivative melting curves obtained after PCR in the presence of unlabeled blocking probes that detect the BRAF c.1799T>A mutation. The melting curve resulting from $100 \%$ wild-type DNA is shown in black, while the $100 \%$ variant DNA is shown in gray. The thin black line is the no-template control. For both DNA templates, the resulting amplicon peak is at $83^{\circ} \mathrm{C}$. The melting peak of the probe/amplicon duplex is $66^{\circ} \mathrm{C}$ for the matched wild-type allele and $62^{\circ} \mathrm{C}$ for the mismatched mutant allele. The detection sensitivity for the 1799A variant depends on the annealing/extension temperature during PCR. Sensitivity is maximal when the annealing/extension temperature is between the Tms of the wild-type and mutant duplex peaks (top). Supporting data for the indicated sensitivities are shown in Supplementary Figure S1.

P-3' were synthesized by Idaho Technology (Salt Lake City, UT, USA). The molecular beacon 5'-FAM-CGGTCTAGCTACAGTGAAATCTCGACCG-BHQ1-3' was synthesized by Biosearch Technologies, Novato, CA, USA). The underlined bases are matched to the c.1799T $>$ A mutation, and "P" signifies a 3 '-phosphate.

PCR and melting analysis

PCR was performed in $10-\mu \mathrm{L}$ reactions containing $2 \mathrm{mmol} / \mathrm{L} \mathrm{MgCl}, 50 \mathrm{mmol} / \mathrm{L}$ Tris (pH 8.3), $500 \mathrm{mg} / \mathrm{L} \mathrm{BSA}, 200 \mu \mathrm{mol} / \mathrm{L}$ of each dNTP, 0.4 units KlenTaq polymerase (Ab Peptides, St. Louis, MO, USA), $64 \mathrm{ng} / \mu \mathrm{L}$ Anti-Taq monoclonal antibody (eENZYME, Montgomery Village, MD, USA), 0.5x LCGreen Plus (Idaho Technology), and 50 or 500 ng human genomic DNA. For symmetric PCR, both primers were at $0.5 \mu \mathrm{M}$. For asymmetric PCR, the allele-specific primer was reduced to $0.1 \mu \mathrm{M}$ or $0.05 \mu \mathrm{M}$. In experiments with blocking probes, the allele-specific primer was at $0.05 \mu \mathrm{M}$ with a probe concentration of $0.5 \mu \mathrm{M}$.

Eighty cycles of rapid-cycle PCR was performed on a LightCycler 1.5 (Roche Applied Science, Indianapolis, IN, USA) after an initial denaturation $95^{\circ} \mathrm{C}$ for $1 \mathrm{~min}$, unless otherwise specified. When an unlabeled probe or no probes were used, each cycle consisted of a $95^{\circ} \mathrm{C}$ denaturation for $0 \mathrm{~s}$ and $\mathrm{a} 64^{\circ} \mathrm{C}$ annealing/extension phase for $4 \mathrm{~s}$ with programmed transitions of $20^{\circ} \mathrm{C} / \mathrm{s}$. Following PCR, a melting protocol from $55^{\circ} \mathrm{C}$ to $92^{\circ} \mathrm{C}$ with a $0.2^{\circ} \mathrm{C} / \mathrm{s}$ ramp rate was used. The protocols for dual hybridization and molecular beacon probes were similar except the annealing/extension phase of PCR was $64^{\circ} \mathrm{C}$ for 0 s and $0.1^{\circ} \mathrm{C} / \mathrm{s}$ ramp between $50^{\circ} \mathrm{C}$ and $75^{\circ} \mathrm{C}$ was used for melting. The second derivative method (24) was used to determine quantification cycle $(\mathrm{Cq})$ values (25).

\section{Single-copy DNA amplification}

Digital PCR was performed by diluting $B R A F$ c.1799A genomic DNA to less than one copy per reaction in the presence or absence of wild-type DNA. Approximately 48 copies $(0.144 \mathrm{ng})$ of c.1799A DNA were amplified across the 96 wells of the LC 480 (Roche) after an initial denaturation at $95^{\circ} \mathrm{C}$ for $3 \mathrm{~min}$ followed by 40 cycles of $95^{\circ} \mathrm{C}$ for $10 \mathrm{~s}$ and $64^{\circ}$ for $15 \mathrm{~s}$. In a separate experiment, 10 copies $(0.030 \mathrm{ng})$ of c.1799A DNA admixed with $3.2 \times 10^{6}$ copies $(10 \mu \mathrm{g})$ wild-type genomic DNA (0.0003\% mutant DNA) were amplified after separation into 20 reactions on a LightCycler 1.5, using the unlabeled probe cycling conditions.

\section{Results and discussion}

Allele-specific PCR is widely used to enrich rare alleles. Specificity is obtained by matching the 3 '-end of one primer to the desired allele. Other alleles are mismatched and their amplifications are inhibited. Inhibition is not complete, however, and mismatched alleles are amplified to various extents depending on the type of mismatch $(26,27)$. The lowest rare-allele percentage that can be distinguished from pure wild-type DNA establishes the sensitivity of the method and is conveniently studied by real-time PCR. Lowering the $\mathrm{Mg}^{2+}$ and the primer concentrations can increase sensitivity and lower the false-positive rate (28).
We enhanced allele-specific PCR amplification and detection by using asymmetric PCR, a wild-type blocking probe, and probe melting analysis. Rare allele enrichment was optimal with an excess of blocking probe and reverse primer compared with the allelespecific primer. Using the $B R A F$ c.1799A single base mutation, as the concentration of the allele-specific primer decreased from $0.5 \mu \mathrm{M}$ to $0.1-0.05 \mu \mathrm{M}$ (in the absence of blocking probes), specificity increased while PCR efficiency decreased. Increasing specificity was reflected during real-time PCR by the $\triangle \mathrm{Cq}$ between wild-type and $B R A F$ DNA increasing from 10 to $19-20$ cycles. Decreasing PCR efficiency was evidenced by an increase in the Cq of $B R A F$ DNA by $12-15$ cycles. Although PCR efficiency was affected by decreasing the concentration of either primer, only lower concentrations of the allele-specific primer increased specificity. In order to compensate for the lower PCR efficiency, 80 cycles were typically performed, but this required only $30 \mathrm{~min}$ using rapidcycle PCR (29).

A lower concentration of allele-specific primer produces an excess of one product strand during asymmetric PCR. If melting probes complementary to the excess strand are included, melting signatures can be observed that are specific to the allele under the probe (16). Figure 1 displays derivative melting plots obtained after asymmetric PCR of pure wild-type or BRAF c.1799A DNA using an unlabeled wild-type blocker as the melting probe. The matched wild-type allele melts about $4^{\circ} \mathrm{C}$ higher than the mismatched mutant allele. Similar to allele-specific competitive blocker PCR (13), the wild-type probe preferentially binds to wild-type DNA and competes with primer binding. At the same time, the allele-specific primer is matched to and preferentially extends the rare allele. Both allele-specific extension and wild-type blocking enhance enrichment and sensitivity for detecting the rare allele.

Allele-specific enrichment with a blocking probe is affected by the annealing/extension temperature of rapid-cycle, two-step PCR. Specificity is optimal when the annealing/ extension temperature is between the melting temperatures $(\mathrm{Tm})$ of the wild-type blocking probe for the matched wild-type allele and the mismatched mutation allele. As the annealing/extension temperature was varied from $60^{\circ} \mathrm{C}$ to $68^{\circ} \mathrm{C}$, detection sensitivity reached a maximum of $0.001 \%$ at $64^{\circ} \mathrm{C}$ (Figure 1, top and Supplementary Figure S1, panel 3), between the two peaks where discrimination between wild-type and mutant DNA is greatest. If the annealing temperature is lower than or equal to the Tm of the mutant allele $\left(62^{\circ} \mathrm{C}\right)$, the probe suppresses amplification of both wild-type 
A

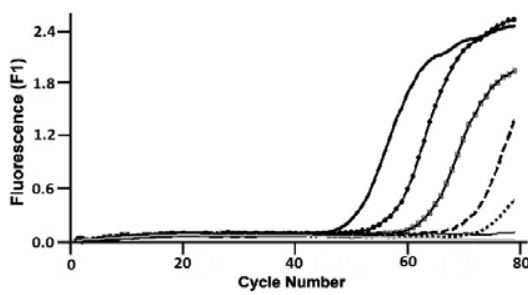

C

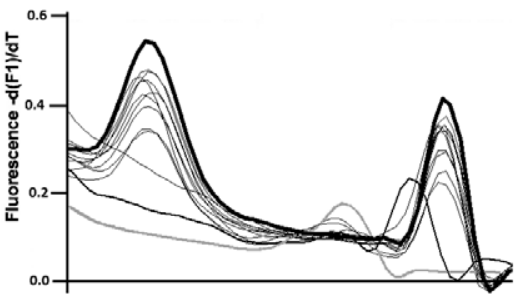

B

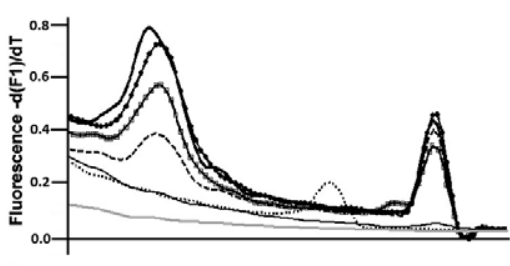

D

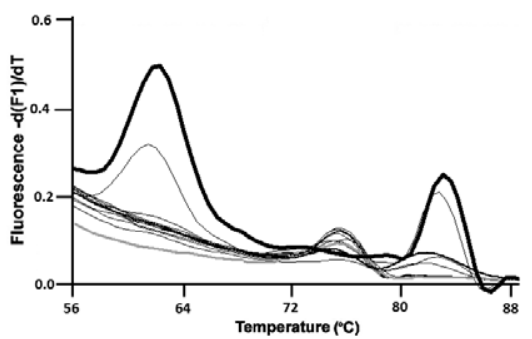

Figure 2. Real-time PCR (A) and melting analysis (B-D) of allele-specific, competitive blocking, asymmetric $\mathrm{PCR}$ with an unlabeled probe in the presence of $\mathbf{5 0} \mathbf{n g}$ of total DNA. In panels $A$ and $B$, the percentage of c. $1799 \mathrm{~A}$ DNA is $10 \%$ (thick solid line), $1 \%$ (large dots), $0.1 \%$ (squares), $0.01 \%$ (dashes), and $0.001 \%$ (dots). The gray line is the no-template control and the thin black line is pure wild-type DNA. The apparent amplification of the $0.001 \%$ sample by real-time PCR is clearly nonspecific when analyzed by melting. The unlabeled probe melting peak for the $1799 \mathrm{~A}$ allele is at $62^{\circ} \mathrm{C}$ and the intended PCR product peak is at $83^{\circ} \mathrm{C}$. In panels $\mathrm{C}$ and D, 100\% mutant DNA (thick black), 100\% wild-type DNA (intermediate black), and no-template DNA (thick gray) controls are shown. The thin gray lines are 10 replicates of 1.7 copies of mutant DNA per tube in panel $\mathrm{C}$, or 0.17 copies of mutant DNA per tube in panel D.

and mutant alleles, limiting the sensitivity to $0.1 \%-0.01 \%$ (Supplementary Figure S1, panels 1 and 2). If the annealing temperature is higher than or equal to the Tm of the wild-type allele $\left(66^{\circ} \mathrm{C}\right)$, preferential blockage and PCR efficiency decrease, also limiting sensitivity to $0.01 \%$ (Supplementary Figure S1, panels 4 and 5). Although rapid-cycle PCR was usually performed, similar results were obtained on more conventional plate instruments. This is in contrast to rare allele detection with snapback primers, where rapid cycling was critical (30).

Using optimal oligonucleotide concentrations and cycling conditions, the sensitivity of the asymmetric melting method was determined with and without wild-type blocking probes. With no probe, the sensitivity determined from the real-time curves was $0.1 \%$ (data not shown). This is similar to other reports using allele-specific primers (31). Sensitivity increased $\geq 10$-fold when an unlabeled probe blocked the wild-type allele and $50 \mathrm{ng}\left(1.7 \times 10^{4}\right)$ total genomic DNA was present (Figure 2). Although allele-specific PCR with competitive blocking greatly reduces amplification of wild-type DNA, false positives may still occur when real-time PCR is used without melting analysis. In Figure 2A, the $0.001 \%$ sample appears to amplify at high cycles. However, both the probe peak and the target amplicon $\left(\mathrm{Tm}=83^{\circ} \mathrm{C}\right)$ are missing for this sample and a different undesired product is present $\left(\mathrm{Tm}=75^{\circ} \mathrm{C}\right)$, indicating nonspe- cific amplification (Figure 2B). By melting the blocking probe, the mutant melting peak confirms that $0.01 \%$ mutant DNA ( 1.7 copies/ tube) was amplified, while $0.001 \%(0.17$ copies/tube) was not. To further investigate the reproducibility of these results, 10 tubes were amplified and melted with an average of 1.7 mutant copies per tube (Figure 2C). Nine of the 10 tubes clearly showed an unlabeled probe melting peak, while one tube did not. This is close to the expected stochastic result predicted by the Poisson equation where $\geq 1$ copy should be present $82 \%$ of the time, with zero copies present $18 \%$ of the time. Similarly, when 10 tubes were amplified with an average of 0.17 copies per tube, 9 had no evidence of a probe peak while 1 clearly was positive (Figure 2D). This is also very close to the Poisson prediction of $16 \%$ of samples containing $\geq 1$ copy and $84 \%$ with 0 copies.

Rare allele detection by probe melting analysis is more specific than real time PCR because the Tm of the probe/allele hybrid confirms the presence of the mutant allele. In contrast, real-time PCR without probes cannot distinguish the intended PCR product from primer dimers and other nonspecific PCR products. The method is enabled by hybridization probes that provide a melting signature. Hydrolysis probes cannot be used because the competition between the probe blocker and primer does not allow probe hydrolysis. Labeled hybridization probes like dual-hybridization probes and molecular beacons have the potential for multicolor analysis. However, unlabeled probes have the advantages of low cost and additional confirmation of the correct product by the amplicon melting peak.

To assess the potential for even greater sensitivity, samples with different mutant percentages were amplified in a total of $500 \mathrm{ng}\left(1.7 \times 10^{5}\right.$ copies) DNA (Figure 3$)$. Dual hybridization probes (Figure 3B) and molecular beacons (Figure 3C) were designed to anneal to the same region as the unlabeled probe design (Figure 3A), each complementary to the wild-type sequence with the same Tm. Unlabeled probes, dual-hybridization probes, and molecular beacons all had a sensitivity of $\geq 0.001 \%$ when used as blocking probes. Samples with $0.001 \%$ mutant DNA (1.7 copies/tube) had identifiable probe melting peaks of the mutant allele, while samples with $0.0001 \%$ mutant DNA (0.17 copies/tube) did not.

To verify that the method detects the presence or absence of a single template copy, 48 copies of genomic BRAF mutant DNA were distributed across the wells of a 96-well plate and amplified. The melting curves clearly clustered into 2 groups with 43 positive and 53 negative results (data not shown). The ability of melting analysis to distinguish the presence or absence of single-copy templates without probes has been previously reported (32). Similar results have been reported for digital PCR with labeled probes, where the complexity of the genomic background is limited (33). However, specific amplification becomes more difficult as the concentration of background wild-type DNA increases. Nevertheless, when 10 copies of BRAF mutant DNA were admixed with $10 \mu \mathrm{g}$ wild-type DNA $\left(3.4 \times 10^{6}\right.$ copies $)$ and amplified in 20 PCR capillaries, 7 out of 20 reactions were positive by melting analysis. Even in the presence of $>10^{5}$ copies of wild-type DNA, single mutant DNA molecules were easily distinguished from the complete absence of mutant DNA. The sensitivity may even be greater, but testing is difficult because of the high DNA concentrations and/or PCR volumes required. If a mutant copy is present in the sample, it will be detected without the risk of false-positive reactions.

Increased sensitivity was demonstrated on 91 clinical thyroid samples previously tested for BRAF c.T1799A (43 positive, 48 negative) by dual-hybridization probes (30). These samples were blinded and reanalyzed by the unlabeled probe method described above. All samples were concordant except for an additional four samples that were positive by the allele-specific method. Detection of $B R A F$ c.T1799A increased in these clinical samples by $9.3 \%$ when the allele-specific, competitive blocking method with melting was used. 
A

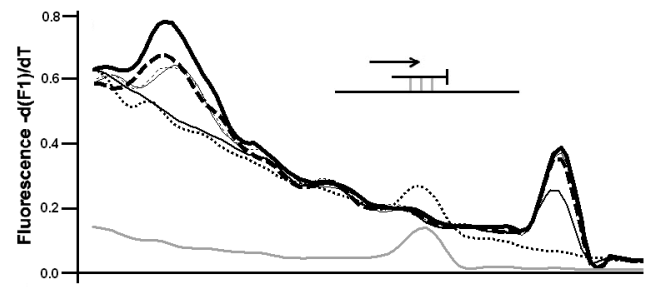

B

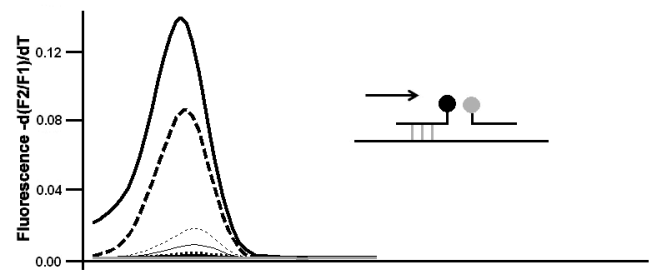

C

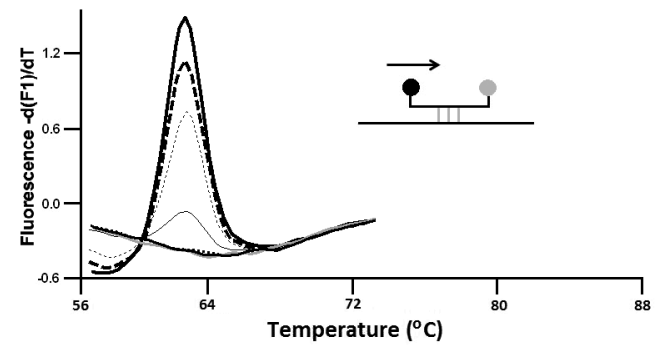

Figure 3. Derivative melting curves of allele-specific, competitive blocking, asymmetric PCR. (A) Unlabeled probes, (B) dual-hybridization probes, and (C) molecular beacons. The percentage of c.1799T>A DNA in 500 ng total DNA is: $1 \%$ (thick solid line), $0.1 \%$ (large dots), $0.01 \%$ (squares), $0.001 \%$ (dashes), and $0.0001 \%$ (small dots). The gray line is the no-template control and the thin black line is 50 ng pure wild-type DNA. Probe- and allelespecific primer schematics are shown in each panel.

The enrichment method used here is similar to allele-specific competitive blocker PCR that is typically analyzed on agarose gels (13) or by internal hydrolysis probes (15). However, the blocker oligonucleotide serves a dual purpose: both blocking wild-type DNA and indicating the presence of mutant alleles by melting analysis. Asymmetric PCR is employed to increase allele-specific amplification and augment detection of the melting signal. Detection of the mutant allele by melting prevents false-positive results, even with $>10^{5}$-fold excess of wild-type DNA. Unlabeled, dual hybridization, and molecular beacon probes can all function as blockers with similar sensitivities. Unlabeled probes are low in cost, while dual hybridization and molecular beacon probes can be multiplexed by color. The method is fast, performed in a closed tube, and should work on any thermocycler with melting analysis capability. The combination of allele-specific priming, competitive probe blocking of wild-type amplification, asymmetric PCR, and probe melting analysis allows single copy detection of variant alleles down to a sensitivity of $\geq 0.001 \%$ mutant to wild-type DNA.

\section{Acknowledgments}

This work was supported by the National Institutes of Health (NIH; grant no. R43GM0882116). This paper is subject to the NIH Public Access Policy.

\section{Competing interests}

Aspects of melting analysis, unlabeled probes and dual-hybridization probes are licensed from the University of Utah to Idaho Technology. C.T.W. has equity interest in Idaho Technology.

\section{Shaking and Mixing for Life Sciences}

\section{The PHMP multifunction three-in-one microplate shaker operates either as a thermoshaker, incubator, or just as a shaker}

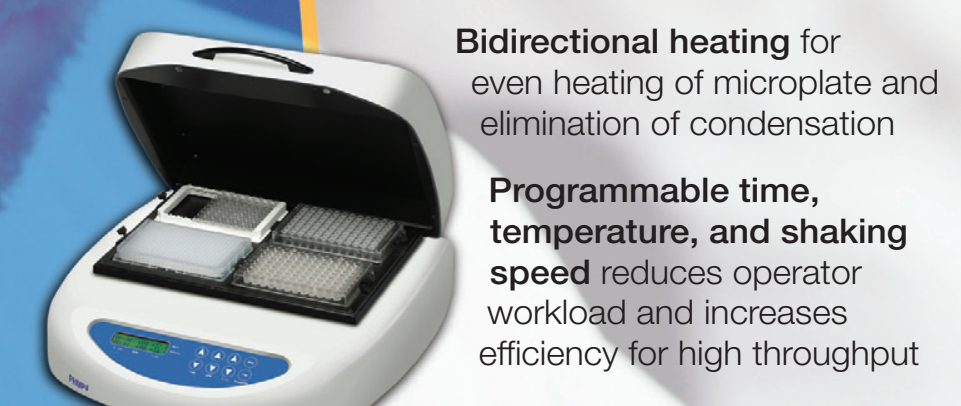

Comprehensive line of reliable rotators, rocker mixers, and shakers for life science applications

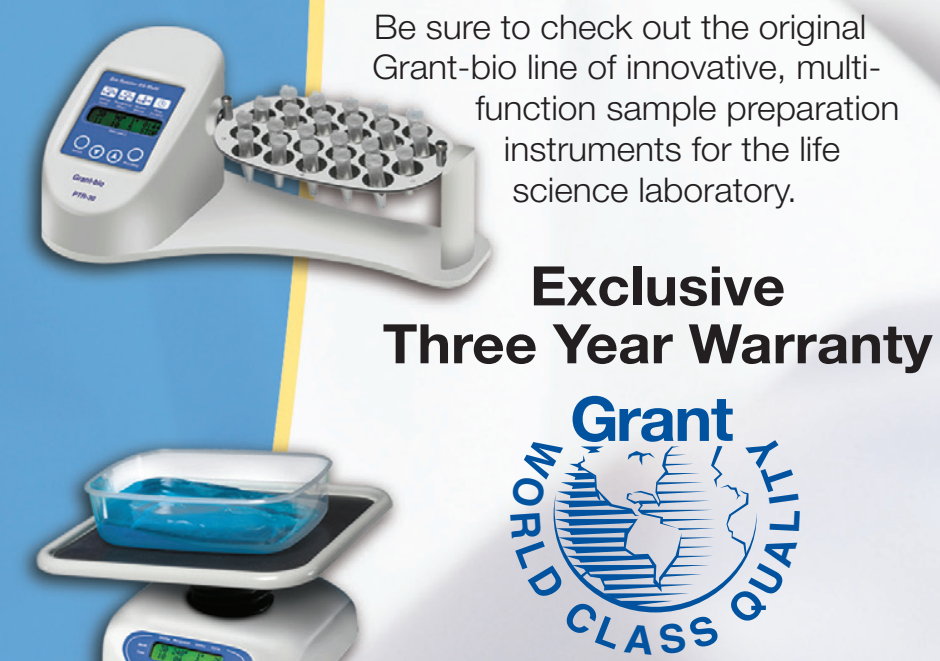

Experience Grant World Class Quality at an Affordable Price-For more information on the Grant-bio line and the name of a dealer nearest you visit www.grantbio.com

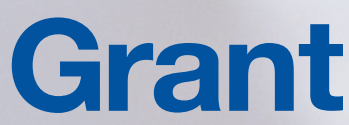

Grant Instruments

601 Route 206, Suite 26-730

Hillsborough, NJ 08844

800-992-3028 • Fax: 908-431-3029 


\section{References}

1. Li, J., L. Wang, H. Mamon, M.H. Kulke, R. Berbeco, and G.M. Makrigiorgos 2008. Replacing PCR with COLD-PCR enriches variant DNA sequences and redefines the sensitivity of genetic testing. Nat. Med. 14:579-584.

2. Newton, C.R., A. Graham, L.E. Heptinstall, S.J. Powell, C. Summers, N. Kalsheker, J.C. Smith, and A.F. Markham. 1989. Analysis of any point mutation in DNA. The amplification refractory mutation system (ARMS) Nucleic Acids Res. 17:2503-2516.

3. Cha, R.S., H. Zarbl, P. Keohavong, and W.G. Thilly. 1992. Mismatch amplification mutation assay (MAMA): application to the c-H-ras gene. PCR Methods Appl. 2:14-20.

4. Levin, J.D., D. Fiala, M.F. Samala, J.D. Kahn, and R.J. Peterson. 2006. Position-dependent effects of locked nucleic acid (LNA) on DNA sequencing and PCR primers. Nucleic Acids Res. 34:e142.

5. Latorra, D., K. Arar, and J.M. Hurley. 2003. Design considerations and effects of LNA in PCR primers. Mol. Cell. Probes 17:253-259.

6. Chen, C.Y., S.C. Shiesh, and S.J. Wu. 2004. Rapid detection of K-ras mutations in bile by peptide nucleic acid-mediated PCR clamping and melting curve analysis: comparison with restriction fragment length polymorphism analysis. Clin. Chem. 50:481-489.

7. Iwamoto, T. and T. Sonobe. 2004. Peptide nucleic acid-mediated competitive PCR clamping for detection of rifampin-resistant Mycobacterium tuberculosis. Antimicrob. Agents Chemother. 48:4023-4026.

8. Dabritz, J., J. Hanfler, R. Preston, J. Stieler, and H. Oettle. 2005. Detection of Ki-ras mutations in tissue and plasma samples of patients with pancreatic cancer using PNA-mediated PCR clamping and hybridisation probes. $\mathrm{Br}$. J. Cancer 92:405-412.

9. Luo, J.D., E.C. Chan, C.L. Shih, T.L. Chen, Y. Liang, T.L. Hwang, and C.C. Chiou. 2006. Detection of rare mutant K-ras DNA in a single-tube reaction using peptide nucleic acid as both PCR clamp and sensor probe. Nucleic Acids Res. 34:e12.

10.Johnson, M.P., L.M. Haupt, and L.R. Griffiths. 2004. Locked nucleic acid (LNA) single nucleotide polymorphism (SNP) genotype analysis and validation using real-time PCR. Nucleic Acids Res. 32:e55.

11. Alonso, J.L., I. Amoros, and G. Cuesta. 2010. LNA probes in a real-time TaqMan PCR assay for genotyping of Giardia duodenalis in wastewaters. J. Appl. Microbiol. 108:1594-1601.

\section{BioTechniques}

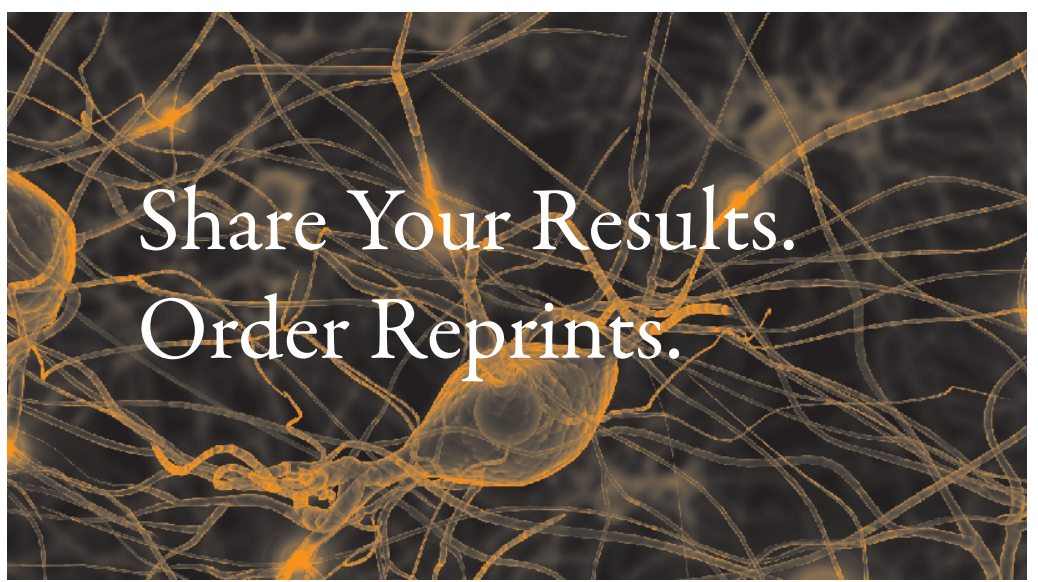

Author Reprints

Make the most of your hard work by ordering reprints of your article published in BioTechniques. Reprints are an inexpensive and easy way to distribute your findings to students and colleagues alike.

\section{Corporate Reprints}

Leverage BioTechniques, the most powerful brand in the market. Reprints help support your sales effort by utilizing articles that spotlight your brand/products to educate customers at meetings and industry trade events.

More info:

www.BioTechniques.com/advertise/reprints
12. Bruge, F., G.P. Littarru, L. Silvestrini, T. Mancuso, and L. Tiano 2009. A novel real time PCR strategy to detect SOD3 SNP using LNA probes. Mutat. Res. 669:80-84

13. Orou, A., B. Fechner, G. Utermann, and H.J. Menzel. 1995. Allelespecific competitive blocker PCR: a one-step method with applicability to pool screening. Hum. Mutat. 6:163-169.

14. McKinzie, P.B., R.R. Delongchamp, T.Chen, and B.L. Parsons. 2006. ACB-PCR measurement of $\mathrm{K}$-ras codon 12 mutant fractions in livers of Big Blue rats treated with N-hydroxy-2-acetylaminofluorene. Mutagenesis 21:391-397.

15. Morlan, J., J. Baker, and D. Sinicropi. 2009. Mutation detection by real-time PCR: a simple, robust and highly selective method. PLoS One 4:e4584.

16.Zhou, L., A.N. Myers, J.G. Vandersteen, L. Wang, and C.T. Wittwer. 2004. Closed-tube genotyping with unlabeled oligonucleotide probes and a saturating DNA dye. Clin. Chem. 50:1328-1335.

17. De Leeneer, K., I. Coene, B. Poppe, A. De Paepe, and K. Claes. 2009 Genotyping of frequent BRCA1/2 SNPs with unlabeled probes: a supplement to HRMCA mutation scanning, allowing the strong reduction of sequencing burden. J. Mol. Diagn. 11:415-419.

18. Bernard, P.S., M.J. Lay, and C.T. Wittwer. 1998. Integrated amplification and detection of the $\mathrm{C} 677 \mathrm{~T}$ point mutation in the methylenetetrahydrofolate reductase gene by fluorescence resonance energy transfer and probe melting curves. Anal. Biochem. 255:101-107.

19. Wittwer, C.T., M.G. Herrmann, C.N. Gundry, and K.S. Elenitoba-Johnson. 2001. Real-time multiplex PCR assays. Methods 25:430-442.

20. Bonnet, G., S. Tyagi, A. Libchaber, and F.R. Kramer. 1999. Thermodynamic basis of the enhanced specificity of structured DNA probes. Proc. Natl. Acad. Sci. USA 96:6171-6176.

21. Kimura, E.T., M.N. Nikiforova,Z.Zhu, J.A. Knauf, Y.E. Nikiforov, and J.A. Fagin. 2003. High prevalence of BRAF mutations in thyroid cancer: genetic evidence for constitutive activation of the RET/PTC-RAS-BRAF signaling pathway in papillary thyroid carcinoma. Cancer Res. 63:1454-1457.

22. Davies, H., G.R. Bignell, C. Cox, P. Stephens, S. Edkins, S. Clegg, J. Teague, H. Woffendin, et al. 2002. Mutations of the BRAF gene in human cancer. Nature 417:949-954

23. Rowe, L.R., B.G. Bentz, and J.S. Bentz. 2006. Utility of BRAF V600E mutation detection in cytologically indeterminate thyroid nodules. Cytojournal 3:10.

24. Wittwer, C.T. and N. Kusukawa. 2011. Real-Time PCR and Melting Analysis, p. 63-82. In D.H. Persing, F.C. Tenover, R. Hayden, F. Nolte, Y.W Tang, and A.V. Belkum (Eds.), Molecular Microbiology: Diagnostic Principles and Practice. ASM Press, Washington, DC.

25. Bustin, S.A., V. Benes, J.A. Garson, J. Hellemans, J. Huggett, M. Kubista, R. Mueller, T. Nolan, et al. 2009. The MIQE guidelines: minimum information for publication of quantitative real-time PCR experiments. Clin. Chem. 55:611-622.

26. Kwok, S., D.E. Kellogg, N. McKinney, D. Spasic, L. Goda, C. Levenson, and J.J. Sninsky. 1990. Effects of primer-template mismatches on the polymerase chain reaction: human immunodeficiency virus type 1 model studies. Nucleic Acids Res. 18:999-1005.

27. Ayyadevara, S., J.J. Thaden, and R.J. Shmookler Reis. 2000. Discrimination of primer 3'-nucleotide mismatch by Taq DNA polymerase during polymerase chain reaction. Anal. Biochem. 284:11-18

28. Sommer, S.S., A.R. Groszbach, and C.D. Bottema. 1992. PCR amplification of specific alleles (PASA) is a general method for rapidly detecting known single-base changes. BioTechniques 12:82-87.

29. Wittwer, C.T., R.P. Rasmussen, and K.M. Ririe. 2010. Rapid PCR and melting curve analysis, p. 48-69. In S.A. Bustin (Ed.), The PCR Revolution: Basic Technologies and Applications. Cambridge University Press, New York.

30.Zhou, L., R.A. Palais, G.D. Smith, D. Anderson, L.R. Rowe, and C.T. Wittwer. 2010. Enrichment and detection of rare alleles by means of snapback primers and rapid-cycle PCR. Clin. Chem. 56:814-822.

31. Milbury, C.A., J. Li, and G.M. Makrigiorgos. 2009. PCR-based methods for the enrichment of minority alleles and mutations. Clin. Chem. 55:632-640.

32. Morrison, T.B., J.J. Weis, and C.T. Wittwer. 1998. Quantification of low-copy transcripts by continuous SYBR Green I monitoring during amplification. BioTechniques 24:954-958, 960, 962

33. Sundberg, S.O., C.T. Wittwer, C. Gao, and B.K. Gale. 2010. Spinning disk platform for microfluidic digital polymerase chain reaction. Anal. Chem. 82:1546-1550.

Received 24 January 2011; accepted 25 March 2011.

Address correspondence to Carl T. Wittwer, $15 \mathrm{~N}$ Medical Drive, Department of Pathology, University of Utah Medical School, Salt Lake City, UT 84132 USA. e-mail: carl.wittwer@path.utah.edu

To purchase reprints of this article, contact: biotechniques@fosterprinting.com 